\title{
Características Físico-Químicas da Carne de Bubalinos e de Bovinos Castrados e Inteiros Victor Cruz Rodrigues ${ }^{1}$, Ivo Francisco de Andrade ${ }^{2}$
}

\begin{abstract}
RESUMO - As características físico-químicas da carne de bovinos Nelore (NE), $\mathrm{F}_{1}$ Nelore x Sindi (NS) e de búfalos Mediterrâneos (BM) castrados e inteiros foram avaliadas. O delineamento experimental foi o inteiramente casualizado em esquema fatorial $3 \times 2$ (três grupos genéticos $\mathrm{x}$ duas condições sexuais) com 24 parcelas. Os animais foram confinados, receberam a mesma dieta e foram abatidos com média de 437,5 kg. As amostras de carne foram obtidas do músculo Longissimus dorsi entre a $11^{\mathrm{a}}$ e $12^{\mathrm{a}}$ costelas. A carne de animais inteiros ofereceu maior teor de umidade $(73,6$ vs $71,0 \%)$, de proteína $(87,5 v s$ 78,6\%) e de minerais $(4,33 v s 3,85 \%)$ e menor teor de gordura $(8,9$ vs $16,8 \%)$ que castrados. A carne de bovinos NE teve maior teor de gordura $(15,4 \%)$ que NS $(12,5 \%)$ e BM $(10,8 \%)$, não havendo diferença para a condição sexual dentro do grupo de BM. A luminosidade, intensidade do vermelho e intensidade do amarelo da carne e da gordura foram semelhantes entre NE, NS e BM, enquanto os castrados alcançaram maior luminosidade $(39,0$ vs 37,2$)$ e intensidade do amarelo $(1,82$ vs 0,87$)$ que inteiros, mas a intensidade do vermelho da carne e a luminosidade, intensidade do vermelho e intensidade do amarelo da gordura foram semelhantes entre grupos genéticos e condição sexual. A carne de BM apresentou menor força de cisalhamento (3,75 kgf) que NS (4,85 kgf) e NE (5,9 kgf), bem como dos castrados (4,5 kgf) em relação aos inteiros (5,2 kgf), mas não houve diferença entre grupo genético e condição sexual para perda por cozimento e para pH final. A carne de búfalos e animais inteiros apresentou menor teor de gordura, sem perder o valor nutritivo, maciez e a baixa perda por cozimento.
\end{abstract}

Palavras-chave: cor, gordura, maciez, perda por cozimento, valor nutritivo

\section{Chemical Physical Meat Characteristics of Buffaloes and Cattle Entire and Castrated}

ABSTRACT - Meat physical and chemical characteristics of Nellore (NE) and $\mathrm{F}_{1}$ Nellore x Sindi (NS) cattle and Mediterranean buffaloes (BM) castrated and entire were evaluated. The experimental design was completely randomized in a factorial arrangement 3 (genetic groups) x 2 (sexual conditions) with 24 plots. Animals were confined, received the same diet and were slaughtered at average weight of $437.5 \mathrm{~kg}$. Meat samples were taken from Longissimus dorsi muscle between $12^{\text {th }}$ and $13^{\text {th }}$ ribs. Castrated and entire animals meat obtained higher moisture ( $73.6 \mathrm{vs} 71.0 \%$ ), protein $(87.5 \mathrm{vs} 78.6 \%)$, ash (4.33 vs $3.85 \%)$ and smaller fat ( $8.9 \mathrm{vs} 16.8 \%)$ content. NE cattle meat showed higher fat content (15.4\%) than NS cattle (12.5\%) and BM (10.8\%), but no difference of sexual condition was observed in BM group. Meat and fat luminosity, red intensity and yellow intensity were similar among NE, NS and BM, while castrated reached higher luminosity (39.0 vs 37.2$)$ and yellow intensity ( $1.82 \mathrm{vs} 0.87)$ than entire, but meat red intensity and fat luminosity, red intensity and yellow intensity were similar among genetic groups and between sexual condition. BM meat showed smaller shearing force (3.75 kgf) than NS (4.85 kgf) e NE (5.9 kgf), as well as castrated (4.5 kgf) in relation to entire (5.2 kgf), but no difference was observed among genetic groups and sexual condition from cooking weight loss and final $\mathrm{pH}$. Buffaloes meat and entire animals showed smaller fat content, maintaining the nutritive value and tenderness and decreasing cooking weight loss.

Key Words: color, cooking weight loss, fat, nutritive value, tenderness

\section{Introdução}

$\mathrm{Na}$ atualidade, há uma demanda por alimentos alternativos e saudáveis. A carne de búfalo se apresenta como uma opção por sua equivalência nutritiva à carne bovina, embora exista uma rejeição ocasionada pelo abate de animais velhos e por métodos insatisfatórios de abate, manipulação e comercialização da carne (Mattos et al., 1990).

A água da carne tem influência direta na suculência, na cor e no sabor. Cerca de $0,1 \%$ da água intracelular do tecido muscular é água de constituição, ligada às moléculas do miofilamentos, 5 a $10 \%$ é água interfacial e encontra-se na superfície das proteínas, com mobilidade relativamente restrita, permancendo líquida mesmo após congelamento. $\mathrm{O}$ restante, de 90 a $95 \%$ da água intracelular, sofre atração das proteínas. Há, ainda, a água dos espaços extracelulares, cerca de $10 \%$ da água do músculo vivo (Felício, 1999).

$\mathrm{Na}$ avaliação da carne de bovinos Nelore e de búfalos Mediterrâneo e Jafarabadi, Mattos et al. 
(1997) não encontraram diferença para umidade (74,6 versus 74,3 e 74,8) e para suculência $(32,2$ versus 29,3 e $30,9 \%$ ). Intrieri et al. (1972) não registraram diferença para umidade da carne entre búfalos inteiros e castrados $(74,1$ versus $73,9 \%)$ e Paleari et al. (2000) relataram diferença entre a carne de búfalas e vacas, respectivamente, de 62,9 e $60,9 \%$ de umidade. Silva et al. (2002) verificaram valores para o músculo Longissimus dorsi de novilhas Eurozebu variando de 74,3 a 75,2\% e Vaz et al. (2001) obtiveram maior valor de umidade na carne de animais inteiros em relação aos castrados Charolês $\mathrm{x}$ Nelore (71,9 versus 70,8\%).

Mattos et al. (1997), ao avaliarem a carne de bovinos Nelore e de búfalos Mediterrâneo e Jafarabadi, não obtiveram diferença para o teor de proteína (23,3 versus 22,7 e 21,8\%), enquanto Intrieri et al. (1972) notaram pequena diferença para proteína da carne de búfalos castrados em relação aos inteiros (23,1 versus 22,0\%). Paleari et al. (2000), por sua vez, encontraram diferença em favor da carne de vaca para o teor de proteína bruta $(31,9$ versus $29,8 \%$ ) em relação à carne de búfala, ao passo que Silva et al. (2002) obtiveram valores de 22,0 a 23,9\% para o músculo Longissimus dorsi de novilhas Eurozebu. Vaz et al. (2001), em análise da carne de animais inteiros em relação aos castrados de grupos Charolês x Nelore, não encontraram diferença, com valor médio em torno de $26,3 \%$.

O teor de gordura na carne é de 3 a $5 \%$, podendo estar classificada como intracelular, intercelular e extracelular. A intracelular se distribui sob a forma de gotículas no plasma celular, enquanto a gordura extracelular constitui a gordura muscular, localizada no tecido conjuntivo (Barros \& Vianni, 1979).

Mattos et al. (1997), ao avaliarem a carne de bovinos Nelore e búfalos Mediterrâneo e Jafarabadi, não encontraram diferença para o teor de gordura (1,2 versus 0,6 e 1,0\%), ao passo que Nascimento et al. (1993) estudaram a composição da carne de búfalos Murrah e obtiveram média de 1,98\% de gordura na amostra de filé, valor abaixo dos obtidos por outros autores, em bovinos.

Estudando o efeito do cobre no metabolismo de lipídeos do músculo Longissimus dorsi, Engle \& Spears (2000) relataram valores de 2,5 a 2,96\% na carne in natura e 9,51 a $9,88 \%$ na base da matéria seca, ao passo que Paleari et al. (2000) não encontraram diferença para gordura da carne de búfalas e de vacas em final de vida reprodutiva $(1,75$ versus
$1,74 \%$ ) e Silva et al. (2002) obtiveram valores para o músculo Longissimus dorsi de novilhas Eurozebu variando de 0,75 a 2,1\%. Intrieri et al. (1972) obtiveram pequena diferença para o teor de gordura da carne de búfalos castrados em relação aos inteiros $(2,44$ versus $1,77 \%)$ e Nascimento et al. (1993) encontraram porcentual médio na carne de búfalos Murrah de 1,98\% de gordura. Vaz et al. (2001) obtiveram maior valor em animais castrados $(2,9$ versus $1,7 \%$ ) em relação aos inteiros Charolês $\mathrm{x}$ Nelore.

Ferrara \& Infascelli (1994) comprovaram que a carne de búfalos tem menor teor de gordura e maior maciez que a de bovinos, em razão da menor taxa de crescimento do diâmetro da fibra muscular, associada à menor consistência do tecido conectivo. Entretanto, Mattos et al. (1997), trabalhando com búfalos Mediterrâneo e Jafarabadi e bovinos Nelore, não encontraram diferença para força de cisalhamento, suculência e teor de gordura. Müller et al. (1994), ao compararem a carne de bovinos Charolês e búfalos Mediterrâneos (BM) verificaram maiores suculência e marmoreio para os bovinos, embora não tenham encontrado diferença para força de cisalhamento.

Considerando animais abatidos com a mesma idade, os inteiros apresentam carne com menos gordura, enquanto a castração pode melhorar a qualidade da carne, em virtude de maior acentuação da gordura intramuscular (Sainz, 1996). Todavia, a carne de animais castrados pode fornecer maior quantidade de calorias e gorduras saturadas, indesejáveis na dieta humana (Nascimento \& Carvalho, 1993).

A substância mineral do corpo compreende vários elementos em quantidades variáveis, em diferentes partes do corpo, de acordo com suas funções. Intrieri et al. (1972) não encontraram diferença para o teor de cinzas entre búfalos inteiros e castrados (1,14 versus 1,03\%). Mattos et al. (1997), ao avaliarem a carne de bovinos Nelore e de búfalos Mediterrâneo e Jafarabadi, não notaram diferença para o teor de minerais pela obtenção das cinzas $(1,1 \%$ para todos os grupos), do mesmo modo que Paleari et al. (2000) não observaram diferença para o teor de minerais da carne de búfalas e de vacas em final da vida reprodutiva (5,53 versus 5,35\%). Silva et al. (2002) obtiveram valores porcentuais para o músculo Longissimus dorsi de novilhas Eurozebu de 0,95 a 1,05\% de cinzas.

A cor é o atributo da carne que reflete a quantidade e o estado químico de seu principal pigmento, a 
mioglobina, de modo que os músculos mais solicitados apresentam maior proporção de células vermelhas entre as fibras brancas. Os bovinos terminados a pasto se exercitam mais e são abatidos mais velhos. Conseqüentemente, apresentam maior saturação da cor vermelha que os animais confinados (Felício, 1999). O consumidor discrimina a carne escura, porque associa a cor escura a animais maduros, sendo essa relação muitas vezes não verdadeira. Nos animais abatidos com pouca reserva de glicogênio, a carne não atinge $\mathrm{pH}$ baixo para produzir coloração normal, resultando em carne de cor escura, independentemente da idade e maciez (Sainz, 1996).

A refletância mínima no espectro de gordura é derivada, principalmente, do b-caroteno e da hemoglobina. A presença de dioxihemoglobina e de meta-hemoglobina escurecem a cor da gordura, havendo grande diferença nas medidas de transmitância entre as cores claras da gordura. Os resultados demonstraram que a aparência é afetada, principalmente, pela absorbância de caroteno e dos derivados da hemoglobina, da refletância, transmitância, fluorescência das gorduras, refletância e fluorescência dos componentes não-lipídicos, como tecido conectivo e membranas celulares (Irie, 2001). Quanto aos bubalinos, a gordura é branca, como ocorre com a gordura do leite, que apresenta traços de caroteno e elevada quantidade de vitamina A, que justifica a cor apresentada (Nascimento \& Carvalho, 1993).

Trabalhando com carne de bovinos da raça Nelore e búfalos Mediterrâneo e Jafarabadi, Mattos et al. (1997) não observaram diferença de luminosidade (26,3 versus 25,7 e 23,1$)$, intensidade da cor vermelha $(13,3$ versus 14,6 e 11,9$)$ e intensidade da cor amarela (8,3 versus 8,4 e 7,3), ao passo que Failla et al. (1997) observaram, na carne de búfalos e bovinos abatidos aos 18 meses, cor mais escura e pouca luminosidade, enquanto em animais abatidos aos 14 meses, a luminosidade, cor e maciez foram melhores nos bubalinos que nos bovinos. Intrieri et al. (1972) não encontraram diferença para carne de búfalos inteiros e castrados, enquanto Vaz \& Restle (2000) observaram cor mais clara nos bovinos Hereford castrados em relação aos inteiros. Vaz et al. (2001), em bovinos castrados e inteiros de diferentes cruzas Charolês x Nelore, verificaram maior intensidade do vermelho nos inteiros.

Paleari et al. (2000) não registraram diferença para luminosidade, saturação e intensidade do vermelho da carne de búfalos e bovinos, cujos valores foram de 72,2; 63,4 e 9,5 para búfalas e 74,2; 51,4 e 10,1 para vacas, enquanto Müller et al. (1994), trabalhando com carne de bovinos Charolês e búfalos Mediterrâneo abatidos com peso semelhante, em amostras obtidas do lombo, verificaram que a carne dos búfalos apresentou cor mais escura. Em relação à coloração, os bovinos inteiros mostraram maior valor $(2,5$ versus 2,0) em relação aos castrados (Morgan et al., 1993).

A maciez é influenciada pelo tipo e pela quantidade de tecido conectivo, que promove a firmeza, a contração das fibras e a dureza miofibrilar. A textura da carne começa a ser quebrada com a mastigação entre as ligações do tecido conectivo, onde a gordura intramuscular está localizada, de modo que a gordura de infiltração pode prejudicar as ligações fibrosas, facilitando a quebra (Wood, 1990). O nível de marmoreio, além de ser um fator visual para o consumidor, está relacionado à maciez, embora exerça pequena influência na variabilidade na maciez (5 a $11 \%$ ). Pode-se incluir como responsáveis pela maciez o conteúdo e a solubilidade do colágeno, o estado de contração do músculo e a degradação das miofibrilas (Sainz, 1996).

$\mathrm{Na}$ transformação do músculo em carne, estabelece-se inicialmente o rigor mortis, com perda da elasticidade do tecido muscular, que conduz à queda do $\mathrm{pH}$ de 7,0 cerca de 5,6 a 5,8. A segunda fase corresponde a um aumento gradual da maciez (tenderização ou maturação), durante o armazenamento post mortem, mediado por diversas proteases, que são as principais responsáveis pela maciez final. Tem grande importância na maciez da carne o sistema das calpaínas, ativadas pelo cálcio, e das catepsinas que degradam as proteínas miofibrilares, além de exercerem ação sobre as proteínas do tecido conjuntivo, bem como o complexo multicatalítico de proteases que atua sobretudo em peptídeos (Oliveira, 2000; Sensky et al., 2001).

Müller et al. (1994) não encontraram diferença para força de cisalhamento (6,8 versus 5,6 kgf), enquanto Morgan et al. (1993) verificaram carne mais macia para o bovino castrado em relação ao inteiro (4,0 versus 4,2 kgf), medida pela força de cisalhamento, em razão das diferenças na estrutura do colágeno e da possível menor fragmentação das miofibrilas. Porém, Vaz et al. (1999), trabalhando com bovinos Hereford, encontraram carne mais macia e com menor perda por cocção nos animais inteiros. 
Mattos et al. (1997), trabalhando com a carne de bovinos Nelore e búfalos Mediterrâneo e Jafarabadi, não obtiveram diferença para força de cisalhamento (5,5; 5,3 e 5,2 kgf), ao passo que Vaz et al. (2001) constataram que a força de cisalhamento da carne de animais castrados Charolês x Nelore foi menor nos inteiros $(5,2$ versus $8,9 \mathrm{kgf})$. Trabalhando com carne de bovinos Hereford inteiros e castrados, Vaz \& Restle (2000) não verificaram diferença para força de cisalhamento, enquanto Paleari et al. (2000) obtiveram menor força de cisalhamento para carne de vacas em comparação à carne de búfalas $(0,157$ versus $0,189 \mathrm{~kg} \mathrm{~mm}^{-2}$ ).

Durante o cozimento da carne, parte da gordura sólida se dissolve, liberando certa quantidade para o meio. As gorduras intramuscular e externa podem se soltar ou serem recapturadas pelas fibras de proteínas da carne magra. Os líquidos ou a suculência da carne que saem são compostos de água e de mínimas quantidades de proteína, nitrogênio não-protéico e de minerais. Além da água, outros constituintes, juntamente com a gordura, são perdidos durante o cozimento (Goutefongea \& Dumont, 1990).

Robertson et al. (1986), trabalhando com a carne de bovinos e búfalos jovens, não obtiveram diferença para perda por cozimento, que variou de 29,1 a $32,5 \%$ para bovinos e de 29,2 a $31,9 \%$ para búfalos. Morgan et al. (1993) não encontraram diferença entre os grupos estudados, inteiros e castrados $(22,4$ versus $23,2 \%$ ). Trabalhando com búfalos e bovinos, Failla et al. (1997) registraram 9\% a mais de perda por cozimento para carne de búfalos. A quebra pela cocção foi maior na carne dos animais castrados (30,1 versus $25,5 \%)$ em experimento realizado com bovinos cruzados Charolês x Nelore (Vaz et al., 2001).

$\mathrm{O}$ pH normal do músculo vivo é de, aproximadamente, 7,0 e diminui até 5,3 a 5,6 após o abate, quando o estado de rigor se desenvolve lentamente. Em rápido declínio, antes de a carcaça perder seu calor natural e de seu metabolismo pelo resfriamento, haverá desnaturação da proteína, provocando redução de sua solubilidade e diminuindo a capacidade de retenção de água e a intensidade da cor, apresentando aspecto pálido e úmido. Por outro lado, o músculo que mantém alto o $\mathrm{pH}$ tem coloração muito escura e a sua superfície exposta é muito seca, uma vez que a água está fortemente ligada à proteína (Barros \& Vianni, 1979).

Mattos et al. (1997), trabalhando com bovinos Nelore e búfalos Mediterrâneo e Jafarabadi, não obtiveram diferença do $\mathrm{pH}(5,6$ versus 5,5 e 5,6$) 24$ horas após o abate. Intrieri et al. (1972) não obtiveram diferença para o $\mathrm{pH}$ da carne, mantida em câmara fria por 48 horas após o abate, de búfalos inteiros $(6,9 \mathrm{a} 6,0)$ e castrados (6,8 a 5,9). Vaz \& Restle (2000) obtiveram pH maior em bovinos Hereford castrados em relação aos inteiros $(6,2$ versus 5,5$) 24$ horas após abate. Também não houve diferença no trabalho de Paleari et al. (2000), em que o $\mathrm{pH}$ da carne de búfalas e vacas após o descongelamento foi, respectivamente, de 5,57 e 5,75.

Considerando que as diferenças para características físicas e químicas da carne de búfalos e bovinos, castrados e inteiros ainda são pouco precisas, objetivou-se, com este trabalho, comparar as carnes de animais que receberam o mesmo manejo e a mesma dieta, abatidos com pesos semelhantes.

\section{Material e Métodos}

Este trabalho foi conduzido no campus da UFRuralRJ, em Seropédica, RJ, com período experimental de 112 dias em confinamento, utilizando-se três grupos genéticos (bovinos Nelore - NE e $F_{1}$ Nelore $x$ Sindi - NS e búfalos Mediterrâneos -BM) com oito animais cada e, duas condições sexuais (castrados e inteiros), totalizando 24 animais. A dieta foi a mesma (Tabela 1) e foi fornecida à vontade, uma vez por dia, iniciando com, no mínimo, $900 \mathrm{~g}$ de proteína bruta por dia e, no máximo, $57,0 \%$ do peso vivo em fibra em detergente neutro (FDN) na matéria seca total.

Os animais apresentaram, no início do período experimental, 284,1 $(25,0) \mathrm{kg}$ e foram abatidos, após jejum de 18 horas, com peso médio de 437,5 $(16,7) \mathrm{kg}$, o que equivale a ganho de $1,36(0,18) \mathrm{kg} / \mathrm{dia}$. Após o resfriamento da carcaça por 48 horas a $1{ }^{\circ} \mathrm{C}$, foram retiradas amostras do músculo Longissimus dorsi entre a $11^{\mathrm{a}}$ e $12^{\mathrm{a}}$ costelas e congeladas. Após 60 dias, procedeu-se às análises físico-químicas. As amostras foram descongeladas em geladeira e retirados nervos, gordura separável e tecido conjuntivo, ficando a carne magra. Em seguida, foram trituradas em processador comercial.

$\mathrm{O}$ teor de umidade foi determinado pela secagem de $10 \mathrm{~g}$ de amostra em placa de Petri com o fundo coberto com areia tratada e pequena baqueta de vidro em estufa a $105^{\circ} \mathrm{C}$, por 24 horas. O uso de areia visou facilitar a determinação dos lipídeos totais, posteriormente, pela facilitação da passagem do éter e extra-

R. Bras. Zootec., v.33, n.6, p.1839-1849, 2004 (Supl. 1) 
Tabela 1 - Formulação da ração utilizada no experimento com base na matéria seca $(\mathrm{kg})$

Table 1 - Formulation of the ration utilized in the experiment based in crude matter $(\mathrm{kg})$

\begin{tabular}{|c|c|c|c|c|}
\hline $\begin{array}{l}\text { Componentes } \\
\text { Components }\end{array}$ & $\begin{array}{l}\mathrm{MS} \\
D M\end{array}$ & $\begin{array}{l}\mathrm{PB} \\
C P\end{array}$ & $\begin{array}{c}\text { FDN* }^{*} \\
N D F\end{array}$ & $\begin{array}{c}\mathrm{EM}^{*} \\
M E\end{array}$ \\
\hline $\begin{array}{l}\text { Capim-elefante } \\
\text { Elephantgrass }\end{array}$ & 1,39 & 0,11 & 1,16 & 1986,2 \\
\hline $\begin{array}{l}\text { Resíduo de cervejaria } \\
\text { Brewers grain }\end{array}$ & 2,47 & 0,51 & 1,56 & 2455,7 \\
\hline $\begin{array}{l}\text { Raspa de mandioca } \\
\text { Cassava scraping }\end{array}$ & 2,63 & 0,14 & 1,09 & 2600,1 \\
\hline $\begin{array}{l}\text { Cama de frango } \\
\text { Broiler litter }\end{array}$ & 0,97 & 0,18 & 0,51 & 2347,3 \\
\hline $\begin{array}{l}\text { Sal mineralizado } \\
\text { Mineralized salt }\end{array}$ & 0,039 & - & - & - \\
\hline Total & 7,499 & 0,94 & 4,32 & 2405,5 \\
\hline
\end{tabular}

*EM - Energia metabolizável ( $\mathrm{kcal} / \mathrm{kg}$ de matéria seca).

*ME - Metabolizable energy (kcal/kg of dry matter).

ção da gordura da amostra. O teor de umidade foi estimado pela média entre as diferenças de peso antes e depois da secagem. A determinação da proteína bruta foi realizada pelo método Kjeldahl, baseado na determinação de nitrogênio total. A digestão foi obtida com ácido sulfúrico, para liberação do carbono, transformação do nitrogênio em amônia, sendo fixada na forma de sal amoniacal. Foi usado o sulfato de cobre, como catalisador oxidante, e o sulfato de potássio, para elevar a temperatura de ebulição. A destilação da solução concentrada de hidróxido de sódio liberou a amônia, que foi destilada em solução de ácido bórico e titulada em solução ácida. O teor de proteína bruta foi obtido utilizando-se o fator 6,25 para multiplicar o nitrogênio total (Silva \& Queiroz, 2002).

As amostras secas empregadas na determinação da umidade foram usadas para extração de lipídeos com éter de petróleo em aparelho de extração "Goldfisch", por 4 horas. A amostra foi transferida para o cartucho, que foi vedado com algodão. O teor de lipídeos foi calculado pela quantidade de gordura que ficou no béquer, previamente pesado, por diferença. A amostra colocada em cadinho foi incinerada a $550^{\circ} \mathrm{C}$ em mufla por 4 horas, obtendose teor de minerais pela diferença de peso da amostra antes e depois de ter sido queimada (Silva \& Queiroz, 2002).

Para determinação da cor foi empregado o sistema colorimétrico, que indica diferenças de cor correspondente a sensibilidade humana. Um pedaço do músculo Longissimus dorsi foi descongelado até a temperatura de $4^{\circ} \mathrm{C}$, por 24 horas, e foi cortado em fatias de $2,5 \mathrm{~cm}$ de espessura e expostas ao ar atmosférico por 30 minutos, fazendo-se a leitura na superfície de todos os lados de cada amostra, no total de seis, com colorímetro Minolta Chroma Meter, calibrado para um padrão brando em ladrilho. O sistema de avaliação adotado foi o CIELAB, no qual $\mathrm{L}^{*}$ mede a intensidade luminosa; $\mathrm{a}^{*}$, a intensidade do roxo ao verde; e b*, a intensidade do amarelo ao azul. A percepção da cor depende das diferenças, sendo que, para a cor da gordura, foi empregada a mesma metodologia, cuja leitura foi realizada na gordura de cobertura do músculo longissimus dorsi sobre a $12^{\mathrm{a}}$ costela (Felício, 1999).

Para a análise da perda por cozimento, foram empregadas as amostras do músculo Longissimus dorsi, que foram pesadas, envolvidas em papel alumínio e colocadas para assar em chapa préaquecida a $150^{\circ} \mathrm{C}$, sendo viradas freqüentemente até alcançar a temperatura interna de $72^{\circ} \mathrm{C}$, obtida com termômetro de ponta metálica, e retiradas para resfriamento ambiente. A perda de peso de cada amostra foi calculada pela diferenças de peso entre as amostras antes e após o cozimento (Felício, 1999; Oliveira, 2000). Com as amostras cozidas foram retiradas subamostras de $1,5 \mathrm{~mm}$ de espessura no sentido da fibra muscular e levadas ao texturômetro com sistema micro estável, onde se obteve a força de cisalhamento em kgf (Müller, 1980).

As leituras de $\mathrm{pH}$ foram realizadas 24 horas após a esfola e evisceração de cada animal, no músculo semimembranosus, com auxílio de um potenciômetro de bancada Q-400A da marca Quimis equipado com eletrodo de inserção. $\mathrm{O}$ aparelho foi calibrado com solução tampão de pH 4,00 e pH 6,86, sendo a calibragem realizada a cada cinco leituras. A limpeza do eletrodo foi realizada com detergente neutro e água destilada no final das leituras. Para inserção do eletrodo, o músculo foi secionado com a ponta de uma faca. As temperaturas foram obtidas com um termômetro de precisão simultaneamente às medidas de $\mathrm{pH}$.

O delineamento experimental foi o inteiramente casualizado e os tratamentos foram arranjados em um esquema fatorial $3 \times 2$ (três grupos genéticos e duas condições sexuais), sendo um animal a unidade experimental, cujo modelo foi $\mathrm{Y}_{\mathrm{ijk}}=\mathrm{m}+\mathrm{G}_{\mathrm{i}}+\mathrm{S}_{\mathrm{j}}+$ $(G S)_{i j}+e_{i j k}$, em que $Y_{i j k}=$ observação do k-ésimo animal do grupo genético $i$, na condição sexual $\mathrm{j} ; \mathrm{m}=$ constante inerente a cada observação (média geral); 
$\mathrm{G}_{\mathrm{i}}=$ efeito do i-ésimo grupo genético, sendo $\mathrm{i}=1,2 \mathrm{e}$ 3 ( 1 = bovino NE; 2 = bovino NS e 3 , búfalo BM); $\mathrm{S}_{\mathrm{j}}=$ efeito da $\mathrm{j}$-ésima condição sexual, sendo $\mathrm{j}=1 \mathrm{e}$ 2 ( 1 = castrados e $2=$ inteiros $) ;(G S)_{\mathrm{ij}}=$ efeito da interação do grupo genético i e condição sexual j; $\mathrm{e}_{\mathrm{ijk}}=$ erro associado a cada observação, sendo normal e independentemente distribuído com média 0 (zero) e variância $\sigma^{2}$.

\section{Resultados e Discussão}

Os valores porcentuais de água, de gordura, de proteína e de minerais da carne são apresentados na Tabela 2. Não ocorreu interação para os teores de umidade, proteína e minerais. Não houve diferença estatística $(\mathrm{P}>0,05)$ para umidade quando comparados os três grupos genéticos, constatando-se valores semelhantes dentro dos grupos estudados. Entretanto, quando se comparou a condição sexual, houve diferença estatística $(\mathrm{P}<0,05)$. A carne de animais castrados apresentou menor teor de umidade que a dos inteiros (em torno de $2,6 \%$ a menos), considerando que a umidade mais acentuada pode estar relacionada ao menor teor gordura. Segundo Nascimento \& Carvalho (1993) e Sainz (1996), verificou-se maior teor de gordura nos animais castrados em relação aos animais inteiros, o que pode ter promovido diminuição no teor de umidade. Os resultados estão de acordo com a afirmação de Barros \& Vianni (1979) de que a água se localiza mais nos músculos que na gordura e que carcaças mais gordurosas apresentam porcentagens menores de água. Isto porque a substância que mais se liga à água é a proteína e a carne é o elemento mais rico em proteína de uma carcaça. Felício (1999) também registra que a proteína exerce atração sobre a água, podendo-se inferir que uma carne com maior teor de água apresenta maior teor de proteína.

Os valores obtidos para umidade da carne estão dentro da amplitude encontrada para búfalos e bovinos e da faixa de valores apresentada por Barros \& Vianni (1979).

Houve interação entre grupo genético e condição sexual $(\mathrm{P}<0,05)$ para o teor de gordura (Tabela 3$)$. Os bovinos castrados apresentaram maior teor de gordura na carne, resultado esperado, uma vez que essa condição sexual promove maior teor de gordura de marmoreio, confirmando os relatos de Nascimento \& Carvalho (1993) e Sainz (1996).

Ao se considerarem os grupos genéticos isoladamente, registrou-se diferença estatística $(\mathrm{P}<0,05)$ dentro dos dois grupos de bovinos, mas não houve diferença $(\mathrm{P}>0,05)$ dentro do grupo de búfalos para castração. As diferenças foram de 10,9\% em favor dos castrados, dentro do grupo de bovinos $\mathrm{NE}$, de $9,2 \%$ dentro do grupo de NS e de $3,7 \%$ dentro do grupo de BM, embora não tenha havido diferença entre castrados e inteiros dentro deste grupo. De modo geral, pode-se afirmar que, dentro dos grupos genéticos estudados, a castração promove aumento do teor de gordura entremeada na carne, embora essa diferença não tenha sido evidenciada dentro do grupo de búfalos.

Para os teores de proteína (Tabela 2) obtidos na carne de búfalos e de bovinos, houve diferença estatística para condição sexual $(\mathrm{P}<0,05)$. A carne de animais inteiros foi superior à dos castrados, com cerca de $8,9 \%$ a mais de proteína. As diferenças

Tabela 2 - Composição química da carne de acordo com o grupo genético e a condição sexual Table 2 - Meat chemical composition, according to the genetic group and sexual condition

\begin{tabular}{|c|c|c|c|c|c|c|}
\hline \multirow[t]{2}{*}{$\begin{array}{l}\text { Nutrientes } \\
\text { Nutrients }\end{array}$} & \multicolumn{3}{|c|}{$\begin{array}{l}\text { Grupo genético } \\
\text { Genetic group }\end{array}$} & \multicolumn{2}{|c|}{$\begin{array}{l}\text { Condição sexual } \\
\text { Sexual condition }\end{array}$} & \multirow[t]{2}{*}{$\mathrm{CV}(\%)$} \\
\hline & $\mathrm{NE}$ & NS & BM & $\begin{array}{l}\text { Castrado } \\
\text { Castrated }\end{array}$ & $\begin{array}{l}\text { Inteiro } \\
\text { Entire }\end{array}$ & \\
\hline Umidade (\%) (Moisture, \%) & $71,7 \mathrm{~A}$ & $71,7 \mathrm{~A}$ & $73,7 \mathrm{~A}$ & $71,0 \mathrm{~b}$ & $73,6 \mathrm{a}$ & 2,6 \\
\hline Gordura* $(\%)(F a t *, \%)$ & $15,4 \mathrm{~A}$ & $12,5 \mathrm{~B}$ & $10,8 \mathrm{~B}$ & $16,8 \mathrm{a}$ & $8,9 \mathrm{~b}$ & 19,6 \\
\hline Proteína (\%) (Protein, \%) & $82,6 \mathrm{~A}$ & $82,2 \mathrm{~A}$ & $84,4 \mathrm{~A}$ & $78,6 \mathrm{~b}$ & $87,5 \mathrm{a}$ & 5,1 \\
\hline Minerais (\%) $(A s h, \%)$ & $3,89 \mathrm{~A}$ & $4,11 \mathrm{~A}$ & $4,29 \mathrm{~A}$ & $3,85 \mathrm{~b}$ & $4,33 \mathrm{a}$ & 8,3 \\
\hline
\end{tabular}

Médias seguidas pela mesma letra na linha, maiúsculas para grupo genético e minúsculas para condição sexual, não diferem significativamente $(P>0,05)$ pelos testes de SNK e $F$, respectivamente.

${ }^{*}$ Foi observada interação significativa entre grupo genético e condição sexual.

Averages followed by same letter, upper case for genetic group and lower case for sexual condition, do not differ significatively (P>.05) by SNK and F respectively. * Significant interation between genetic group and sexual condition was observed.

R. Bras. Zootec., v.33, n.6, p.1839-1849, 2004 (Supl. 1) 
Tabela 3 - Interação do porcentual de gordura da carne de acordo com o grupo genético e a condição sexual

Table 3 - Meat fat content interation according to genetic group and sexual condition

\begin{tabular}{lccc}
\hline $\begin{array}{l}\text { Condição sexual } \\
\text { Sexual condition }\end{array}$ & \multicolumn{3}{c}{$\begin{array}{c}\text { Grupo genético } \\
\text { Genetic group }\end{array}$} \\
\cline { 2 - 4 } & $\mathrm{NE}$ & $\mathrm{NS}$ & $\mathrm{BM}$ \\
\hline Castrados & $20,8 \mathrm{Aa}$ & $17,1 \mathrm{Ba}$ & $12,6 \mathrm{Ca}$ \\
$\begin{array}{l}\text { Castrated } \\
\text { Inteiro } \\
\text { Entire }\end{array}$ & $9,9 \mathrm{Ab}$ & $7,9 \mathrm{Ab}$ & $8,9 \mathrm{Aa}$ \\
\hline
\end{tabular}

Médias seguidas pela mesma letra, maiúsculas na linha para grupo genético e minúsculas na coluna para condição sexual, não diferem significativamente $(P>0,05)$ pelos testes SNK e $F$, respectivamente.

Averages followed by the same letter, upper case for genetic group and lower case for sexual condition, do not differ significatively $(P>$.05) by SNK and $F$ tests, respectively.

entre animais inteiros e castrados eram esperadas, considerando que a castração, técnica bastante usada para melhorar a qualidade da carne, aumenta o teor de gordura de infiltração, possivelmente diminuindo o teor de proteína na carne, em razão do maior espaço ocupado. Os resultados corroboram os de Sainz (1996), que constatou que o conteúdo de gordura é menor no macho inteiro e maior no castrado. Mattos et al. (1997), trabalhando com carne de búfalos e de bovinos, e Vaz et al. (2001), com carne de bovinos, não encontraram diferença para o teor de gordura. Intrieri et al. (1972), por sua vez, encontraram valores diferentes para búfalos castrados, que apresentaram maior teor de proteína que os inteiros.

Para os valores de cinzas (Tabela 2) da carne de búfalos e bovinos, verificou-se efeito da condição sexual sobre o teor de minerais em favor dos inteiros ( $\mathrm{P}<0,05$, cerca de $0,48 \%$ a mais). Estes resultados podem ser atribuídos ao maior teor de músculo e ao menor teor de gordura na carne dos inteiros, favorecendo o aumento do teor de minerais, enquanto a carne rica em gordura promoveu a redução do teor de minerais.

Para o teor de cinzas, Mattos et al. (1997) e Paleari et al. (2000) encontraram valores inferiores, quando compararam a carne de búfalos e bovinos, mas não encontraram diferença estatística entre os dois grupos, ao passo que Intrieri et al. (1972) também não encontraram diferença entre búfalos inteiros e castrados. Os resultados, possivelmente, tiveram influência dos grupos estudados e da metodologia empregada.
Os resultados indicam que, quando o teor de gordura na carne é maior, há tendência de diminuição do teor de umidade, de proteína e de minerais, possivelmente porque a gordura ocupa o espaço no interior da carne desses constituintes. A mesma tendência ocorre com animais castrados, isto é, o maior teor de gordura na carne promove redução dos demais constituintes em relação à carne dos animais inteiros.

Acerca dos males causados pela gordura à saúde humana, é mais saudável consumir carne de búfalos e de animais inteiros. Por outro lado, a carne com maior teor de gordura promove um benefício em relação à maciez, apesar de Muller et al. (1994) não terem encontrado diferença para maciez da carne de BM e bovinos Charolês, com os búfalos apresentando gordura de marmoreio inferior aos bovinos; salientando-se que essa raça bovina é de origem européia e cujo marmoreio é superior ao dos zebuínos e búfalos. Portanto, em bovinos e búfalos, a castração promove aumento do teor de gordura entremeada na carne, embora essa diferença tenha sido observada no grupo de búfalos deste experimento.

Os valores para cor da carne, expressos pela luminosidade, intensidade do vermelho e intensidade do amarelo estão apresentados na Tabela 4. Não houve interação entre grupo genético e condição sexual $(\mathrm{P}>0,05)$ para todas as características fisicoquímicas referentes à cor. Verificou-se, ainda, que entre grupo genético não houve diferença estatística $(\mathrm{P}>0,05)$ para luminosidade e intensidade do vermelho, havendo diferença $(\mathrm{P}<0,05)$ apenas para a intensidade do amarelo. Em relação à condição sexual, houve diferença estatística $(\mathrm{P}<0,05)$ para luminosidade e intensidade do amarelo, não havendo diferença para intensidade do vermelho.

Para luminosidade dentro da condição sexual, houve diferença estatística $(\mathrm{P}<0,05)$, de modo que os castrados apresentaram carne mais clara (maior luminosidade) em relação aos inteiros, com cerca de 1,8 de diferença, que pode ser atribuída ao maior teor de gordura na carne dos castrados, produzindo maior refletância que a carne dos inteiros, com menor teor de gordura.

Observando os valores obtidos para intensidade do vermelho, não houve diferença estatística $(\mathrm{P}>0,05)$ entre grupos genéticos e a condição sexual, indicando que búfalos e bovinos castrados ou inteiros apresentam intensidade da cor vermelha da carne semelhante.

Analisando a intensidade do amarelo da carne, foi constatada diferença estatística entre grupos genéticos 
Tabela 4 - Cor da carne e da gordura, de acordo com o grupo genético e a condição sexual Table 4 - Meat and fat color, according to the genetic group and sexual condition

\begin{tabular}{|c|c|c|c|c|c|c|}
\hline \multirow[t]{2}{*}{$\begin{array}{l}\text { Característica } \\
\text { Characteristic }\end{array}$} & \multicolumn{3}{|c|}{$\begin{array}{l}\text { Grupo genético } \\
\text { Genetic group }\end{array}$} & \multicolumn{2}{|c|}{$\begin{array}{l}\text { Condição sexual } \\
\text { Sexual condition }\end{array}$} & \multirow[t]{2}{*}{$\mathrm{CV}(\%)$} \\
\hline & $\mathrm{NE}$ & NS & $\mathrm{BM}$ & $\begin{array}{l}\text { Castrado } \\
\text { Castrated }\end{array}$ & $\begin{array}{l}\text { Inteiro } \\
\text { Entire }\end{array}$ & \\
\hline \multicolumn{7}{|l|}{ Carne } \\
\hline \multicolumn{7}{|l|}{ Meat } \\
\hline $\begin{array}{l}\text { Luminosidade } \\
\text { Luminosity }\end{array}$ & $37,6 \mathrm{~A}$ & $38,7 \mathrm{~A}$ & $38,0 \mathrm{~A}$ & $39,0 \mathrm{a}$ & $37,2 \mathrm{~b}$ & 5,0 \\
\hline $\begin{array}{l}\text { Int. vermelho } \\
\text { Red intensity }\end{array}$ & $19,5 \mathrm{~A}$ & $18,5 \mathrm{~A}$ & $19,1 \mathrm{~A}$ & $19,3 \mathrm{a}$ & $18,7 \mathrm{a}$ & 5,9 \\
\hline $\begin{array}{l}\text { Int. amarelo } \\
\text { Yellow intensity }\end{array}$ & $1,50 \mathrm{~A}$ & $1,76 \mathrm{~A}$ & $0,78 \mathrm{~B}$ & $1,82 \mathrm{a}$ & $0,87 \mathrm{~b}$ & 43,4 \\
\hline $\begin{array}{l}\text { Gordura } \\
\text { Fat }\end{array}$ & & & & & & \\
\hline $\begin{array}{l}\text { Luminosidade } \\
\text { Luminosity }\end{array}$ & $72,8 \mathrm{~A}$ & $73,9 \mathrm{~A}$ & $75,9 \mathrm{~A}$ & $73,2 \mathrm{a}$ & $75,2 \mathrm{a}$ & 4,1 \\
\hline $\begin{array}{l}\text { Int. vermelho } \\
\text { Red intensity }\end{array}$ & 7,39A & $7,60 \mathrm{~A}$ & $7,24 \mathrm{~A}$ & $7,63 \mathrm{a}$ & 7,19a & 15,5 \\
\hline $\begin{array}{l}\text { Int. amarelo } \\
\text { Yellowintensity }\end{array}$ & $2,15 \mathrm{~A}$ & $1,76 \mathrm{~A}$ & $0,89 \mathrm{~A}$ & $1,92 \mathrm{a}$ & $1,28 \mathrm{a}$ & 65,7 \\
\hline
\end{tabular}

Médias seguidas pela mesma letra na linha, maiúsculas para grupo genético e minúsculas para condição sexual, não diferem significativamente $(P>0,05)$ pelos testes SNK e $F$, respectivamente.

Averages followed by same letter, upper case for genetic group and lower case for sexual condition, do not differ significatively (P>.05) by SNK and $F$ tests, respectively.

e influência da condição sexual $(\mathrm{P}<0,05)$. Os dois grupos de bovinos apresentaram maior intensidade do amarelo que búfalos: as diferenças foram de 0,72 , em relação ao grupo de bovinos $\mathrm{NE}$, e de 0,98 , em relação ao de NS. A intensidade do amarelo foi bem maior (maior deposição de pigmentos carotenóides) nos animais castrados $(\mathrm{P}<0,05)$ em relação aos inteiros, cerca de 0,95 de diferença. A menor intensidade da cor amarela na carne de búfalo, provavelmente, se deve à correlação com o menor teor de gordura na carne de búfalos e à cor mais clara da gordura de marmoreio desses animais. A maior intensidade nos animais castrados, possivelmente, resultou da correlação positiva entre intensidade do amarelo e teor de gordura dos animais castrados.

As diferenças obtidas em outros trabalhos podem ser explicadas pela metodologia utilizada, com animais muito erados ou mais jovens, especialmente no caso dos búfalos. Da mesma forma que tem sido observada textura mais grosseira na carne de búfalo, a cor também pode estar refletindo o fato de a carne ser proveniente de animais muito velhos, como descrevem Mattos et al. (1990). Quando as condições de manejo e alimentação são as mesmas, incluindo a maturidade dos animais, búfalos competem em igualdade de condições para características qualitativas da carne com bovinos.
Mattos et al. (1997) não encontraram diferença para luminosidade e intensidade do vermelho, diferindo dos resultados apenas para a intensidade do amarelo entre a carne de búfalos e bovinos. Paleari et al. (2000) não encontraram diferença de luminosidade e intensidade do vermelho entre búfalas e vacas. Müller et al. (1994) obtiveram resultados diferentes, verificando que os búfalos apresentam cor da carne mais escura que bovinos, assim como Failla et al. (1997), que também obtiveram carne mais escura e de pouca luminosidade em búfalos. Resultados diferentes foram encontrados por Intrieri et al. (1972), que não obtiveram diferença para cor da carne de búfalos inteiros e castrados, enquanto Vaz \& Restle (2000) obtiveram cor mais clara nos bovinos castrados em relação aos inteiros. Vaz et al. (2001) e Morgan et al., (1993) também obtiveram maior intensidade do vermelho na carne de bovinos inteiros. Pelos resultados obtidos, a cor da carne não pode ser limitante para o consumo de carne de búfalos quando comparada à carne de bovinos.

Para os valores de luminosidade, intensidade do vermelho e intensidade do amarelo da gordura (Tabela 4), não houve interação entre grupo genético e condição sexual $(\mathrm{P}>0,05)$ para todas as características estudadas, como também não houve

R. Bras. Zootec., v.33, n.6, p.1839-1849, 2004 (Supl. 1) 
Tabela 5 - Força de cisalhamento, perda pelo cozimento e pH final da carne de acordo com o grupo genético e a condição sexual

Table 5 - Meat Shear force, decoct lost and at last $\mathrm{pH}$, according to the genetic group and sexual condition

\begin{tabular}{|c|c|c|c|c|c|c|}
\hline \multirow[t]{2}{*}{$\begin{array}{l}\text { Característica } \\
\text { Characteristic }\end{array}$} & \multicolumn{3}{|c|}{$\begin{array}{l}\text { Grupo genético } \\
\text { Genetic group }\end{array}$} & \multicolumn{2}{|c|}{$\begin{array}{l}\text { Condição sexual } \\
\text { Sexual condition }\end{array}$} & \multirow[t]{2}{*}{$\mathrm{CV}(\%)$} \\
\hline & $\mathrm{NE}$ & NS & $\mathrm{BM}$ & $\begin{array}{l}\text { Castrado } \\
\text { Castrated }\end{array}$ & $\begin{array}{l}\text { Inteiro } \\
\text { Entire }\end{array}$ & \\
\hline $\begin{array}{l}\text { Força de cisalhamento (kgf) } \\
\text { Shear force (kgf) }\end{array}$ & $5,9 \mathrm{~A}$ & $4,85 \mathrm{~B}$ & $3,75 \mathrm{C}$ & $4,5 \mathrm{~b}$ & $5,2 \mathrm{a}$ & 9,8 \\
\hline $\begin{array}{l}\text { PPC }(\%) \\
\text { Decoct lost }(\%)\end{array}$ & $30,7 \mathrm{~A}$ & $32,7 \mathrm{~A}$ & $32,0 \mathrm{~A}$ & $29,5 \mathrm{a}$ & $34,0 \mathrm{a}$ & 17,5 \\
\hline $\begin{array}{l}\text { pH final } \\
\text { pH at last }\end{array}$ & $5,42 \mathrm{~A}$ & $5,41 \mathrm{~A}$ & $5,66 \mathrm{~A}$ & $5,50 \mathrm{a}$ & $5,49 \mathrm{a}$ & 1,8 \\
\hline
\end{tabular}

Médias seguidas pela mesma letra na linha, maiúsculas para grupo genético e minúsculas para condição sexual, não diferem significativamente $(\mathrm{P}>0,05)$ pelos testes de SNK e $\mathrm{F}$, respectivamente.

Averages followed by same letter, upper case for genetic group and lower case for sexual condition, do not differ significatively (P>.05) by SNK and $F$ tests, respectively.

diferença estatística $(\mathrm{P}>0,05)$ entre grupo genético e condição sexual. A cor da gordura de búfalos e de bovinos castrados e inteiros, determinada pela luminosidade, intensidade do vermelho e intensidade do amarelo, foi semelhante.

Também não houve diferença estatística $(\mathrm{P}>0,05)$ entre grupo genético e efeito da condição sexual para a intensidade do amarelo da gordura. Entretanto, observou-se que os búfalos tenderam a apresentar valor bem inferior aos dois grupos de bovinos $(\mathrm{P}=0,073)$ para essa variável, embora não tenha ocorrido significância $(\mathrm{P}>0,05)$. A diferença para a intensidade do amarelo da gordura entre o grupo de bovinos NE e BM foi de 1,26 e de NS e BU, de 0,87 . Essas diferenças foram semelhantes ou maiores que o valor obtido para o grupo de búfalos.

Os búfalos podem apresentar gordura com menor intensidade do amarelo, graças à presença de gordura branca, a exemplo do que ocorre com a gordura do leite, com traços de caroteno e elevado teor de vitamina A, como descreve Nascimento \& Carvalho (1993). Todavia, esta intensidade não foi evidenciada neste estudo. A aparência da gordura, principalmente afetada pela absorbância de caroteno e dos derivados da hemoglobina, tendo como conseqüência maior intensidade do amarelo (Irie, 2001), não foi maior na gordura dos bovinos, considerando que essa gordura pode ter maior proporção de caroteno.

Os valores para força de cisalhamento, perda por cozimento e pH final da carne estão apresentados na Tabela 5. Não houve interação entre grupo genético e condição sexual $(\mathrm{P}>0,05)$ para força de cisalhamento. Entretanto, houve diferença estatística $(\mathrm{P}<0,05)$ entre os grupos genéticos e influência da condição sexual. A carne de bovinos NE apresentou maior força de cisalhamento, reflexo de menor maciez, seguida pela dos bovinos NS e, por último, dos BM. A diferença foi de $1,05 \mathrm{kgf}$ em relação ao $1 / 2 \mathrm{NS}$ e de $2,15 \mathrm{kgf}$ em relação à carne de búfalo. A diferença entre a força de cisalhamento exercida sobre a carne do $1 / 2 \mathrm{NS}$ e a de BM foi de $1,1 \mathrm{kgf}$.

$\mathrm{O}$ búfalo apresentou a carne com menor força de cisalhamento, comprovando que a carne de búfalo não é dura, como popularmente se divulga. Provavelmente, esta desinformação existe porque os búfalos, muitas vezes, são abatidos em idade muita avançada e de modo inadequado, como registra Mattos et al. (1990), especialmente quando criados em sistema extensivo, muitas vezes tendo que ser caçados. Os resultados foram diferentes dos achados de Müller et al. (1994) e Mattos et al. (1997), que não obtiveram diferença para maciez entre a carne de búfalos e de bovinos. A maior maciez pode ter relação com a maturidade, uma vez que animais mais jovens apresentam carne de maior maciez. Búfalos podem ser abatidos com o mesmo peso que bovinos em menor idade cronológica, em razão de seu grande desenvolvimento ponderal, podendo promover maior maciez da carne.

Houve efeito $(\mathrm{P}<0,05)$ da condição sexual sobre a força de cisalhamento da carne. Os animais castrados apresentaram maior maciez que os inteiros, com diferença de 0,7 kgf. Esse resultado era esperado, pois animais castrados oferecem maior proporção de 
gordura entremeada, melhorando a maciez, como descrito por Morgan et al. (1993), mas diferente dos resultados de Vaz et al. (1999), que, em bovinos Hereford, encontraram maior maciez nos inteiros. Analisando os grupos genéticos isoladamente, entre bovinos NE e NS, os castrados apresentaram maior maciez $(\mathrm{P}<0,05)$, mas dentro do grupo de búfalos não ocorreu diferença estatística $(\mathrm{P}>0,05)$, de modo que inteiros apresentaram maciez semelhante aos castrados, possivelmente pelo fato de os búfalos depositarem pouca gordura entremeada na carne, mesmo quando castrados, uma característica da espécie.

Não houve interação entre grupo genético e condição sexual $(\mathrm{P}>0,05)$, como também não ocorreu efeito do grupo genético e da condição sexual sobre a perda por cozimento da carne de búfalos e bovinos. Como a perda por cozimento está relacionada à suculência, esse resultado indica que búfalos e de bovinos castrados e inteiros apresentam carne adequada ao consumo, não havendo qualquer limitação para uso na culinária (Tabela 5).

Para o declínio $\mathrm{pH}$ post mortem não, houve interação entre grupo genético e condição sexual $(\mathrm{P}>0,05)$, como não ocorreu diferença estatística entre grupo genético e condição sexual $(\mathrm{P}>0,05)$, quando analisados isoladamente. Isto é, não houve diferença para o declínio do $\mathrm{pH}$ post mortem da carne de búfalos e de bovinos, como não houve entre o $\mathrm{pH}$ da carne de animais castrados e inteiros.

A última medida de $\mathrm{pH}$ da carne (Tabela 5) de todos os grupos estudados demonstrou que não pode haver justificativas para condenar a carne de búfalos ou de bovinos, uma vez que a semelhança na queda de $\mathrm{pH}$ é um indicativo de que essas carnes são de boa qualidade, sob condições idênticas de armazenamento.

Pode-se concluir que não há diferenças entre as médias de $\mathrm{pH}$ e que o rigor mortis ocorre de maneira semelhante entre búfalos e bovinos ou entre animais castrados e inteiros. Não existe nenhum comprometimento dos fatores organolépticos relacionados à qualidade da carne vinculados ao $\mathrm{pH}$ nos grupos estudados. Os resultados não diferiram dos achados de Mattos et al. (1997), que não obtiveram diferença de $\mathrm{pH}$ após 24 horas do abate. Paleari et al. (2000) não encontraram diferença para $\mathrm{pH}$ da carne de búfalas e de vacas e Intrieri et al. (1972) não obtiveram diferença para o pH de búfalos inteiros, ao passo que Vaz \& Restle (2000) verificaram resultados diferentes, obtendo $\mathrm{pH}$ maior nos bovinos castrados que nos inteiros.

\section{Conclusões}

Animais castrados apresentam maior teor de gordura na carne que inteiros.

Búfalos e bovinos apresentam teores de umidade, de proteína e de minerais da carne semelhantes, enquanto animais inteiros apresentam teores semelhantes aos castrados.

A carne de búfalos apresentou menor teor de gordura que a de bovinos, o que pode torná-la mais saudável, em decorrência de seu menor teor de gordura entremeada.

Búfalos têm carne mais macia que bovinos Nelore e $F_{1}$ Nelore x Sindi e animais castrados, carne mais macia que inteiros.

Para dietas menos gordurosas, seria recomendável o consumo da carne de búfalo e de animais inteiros.

\section{Literatura citada}

BARROS, G.C.; VIANNI, M.C.E. Tecnologia aplicada às carnes bovina, suína e de aves, da produção ao consumo. Seropédica: Universidade Federal Rural do Rio de janeiro, 1979. $116 \mathrm{p}$.

ENGLE, T.E.; SPEARS, J.W. Dietary copper effects on lipid metabolism, performance and ruminal fermentation in finishing steers. Journal of Animal Science, v.78, n.9, p.2452-2458, 2000.

FAILLA, S.; IACURTO, M.; GIGLI, S. et al. Meat quality characteristics of buffaloes, slaughtered at two different ages in comparison with typical italian beef genotypes. In: WORLD BUFFALO CONGRESS, 5., 1997, Caserta. Proceedings... Caserta: FAO/IBF, 1997. p.447-451.

FELÍCIO, P.E. Qualidade da carne bovina: características físicas e organolépticas. In: REUNIÃO ANUAL DA SOCIEDADE BRASILEIRA DE ZOOTECNIA, 36., 1999, Porto Alegre. Anais ... Porto Alegre: Sociedade Brasileira de Zootecnia, 1999. p.89-97.

FERRARA, B.; INFASCELLI, F. Buffalo meat production. WORLD BUFFALO CONGRESS, 4., 1994, São Paulo. Proceedings... São Paulo: FAO/FINEP, 1994, v.1, p.122-136.

GOUTEFONGEA, R.; DUMONT, J.P. Developments in lowfat meat and meat products. In: WOOD, J.D.; FISHER, A.V. (Eds.) Reducing fat in meat animals. London: Elsevier, 1990. p.398-436.

INTRIERI, F.; ZICARELLI, L.; DI LELLA, T.; RINALDI, G. $\mathrm{Su}$ alcune caratteristiche chimiche, fisiche e chimico-fisiche del muscolo Longissimus dorsi di vitellone bufalino. Acta Medica Veterinaria, v.18, n.1, p.77-87, 1972.

IRIE, M. Optical evaluation of factors affecting appearance of bovine fat. Meat Science, v.57, n.1, p.19-22, 2001.

MATTOS, J.C.A.; GUTMANis, D.; MATtOS, A.C. Características da carcaça e da carne de bubalinos (Conferências). In: REUNIÃO ANUAL DA SOCIEDADE BRASILEIRA DE ZOOTECNIA, 27., Campinas, 1990. Anais... Piracicaba: Fundação de Estudos Agrários Luiz de Queiroz, 1990. p.711-737. 
MATTOS, J.C.A.; NOGUEIRA, J.R.; OLIVEIRA, A.A.D. et al. Comparison on carcass, meat cuts and some meat quality characteristics of buffaloes and zebu. In: WORLD BUFFALO CONGRESS, 5., Caserta, 1997. Proceedings... Caserta: FAO/IBF, 1997. p.442-446.

MORGAN, J.B.; WHEELER, T.L.; KOOHMARAIE, M. et al. Meat tenderness and the calpain proteolytic system in longissimus muscle of young bulls and steers. Journal of Animal Science, v.71, p.1471-1476, 1993.

MÜLLER, L. Normas para avaliação de carcaças e concurso de carcaças de novilhos. Santa Maria: Universidade Federal de Santa Maria, 1980. 31p.

MÜLLER, L.; AGUIRRE, L.F.; RESTLE, J. et al. Carcass and meat quality of cattle and buffalo. In: WORLD BUFFALO CONGRESS, 4., 1994, São Paulo. Proceedings... São Paulo: FAO/FINEP, 1994. v.2, p.130-132.

NASCIMENTO, C.N.B.; CARVALHO, L.O.D.M.; BARBOSA, W.C. Valor nutritivo da carne de búfalos Murrah. Belém: EMBRAPA-CPATU, 1993. 17p. (EMBRAPA-CPATU. Boletim de Pesquisa, 142)

NASCIMENTO, C.N.B.; CARVALHO, L.O.D.M. Criação de búfalos: alimentação, manejo, melhoramento e instalações. Brasília: EMBRAPA/SPI, 1993. 403p.

OLIVEIRA, A.L. Qualidade da carne bovina. Informe Agropecuário, v.21, n.205, p.39-47, 2000.

PALEARI, M.A.; BERETTA, G.; COLOMBO, F. et al. Búfalo meat as a salted and cured product. Meat Science v. 54, n.4, p.365-367, 2000

ROBERTSON, J.; RATCLIFF, D.; BOUTON. P.E. et al. A comparison of some properties of meat from young buffalo (Bubalus bubalis) and cattle. Journal of Food Science, v.51, n.1, p.47-50, 1986.

SAINZ, R.D. Qualidade das carcaças e da carne bovina. In: CONGRESSO BRASILEIRO DAS RAÇAS ZEBUÍNAS, 2., 1996, Uberaba. Anais... Uberaba: Associação Brasileira dos Criadores de Zebu, 1996 (não paginado).
SENSKY, P.L.; PARR, T.; BARDSLEY, R.G.; BUTTERY, P.J. Meat tenderisation - the role of calpains. Proceedings of the British Society of Animal Science. British Society of Animal Science, Midlothian, 2001. p.239-242.

SILVA, R.G.; PRADO, I.N.; MATSUSHITA, M.; SOUZA, N.E. de. Dietary effects on muscle fatty acid composition of finished heifers. Pesquisa Agropecuária Brasileira, v.37, n.1, p.95-101, 2002.

SILVA, D.J.; QUEIROZ, A.C. Análise de alimentos (métodos químicos e biológicos). 3.ed. Viçosa, MG: Universidade Federal de Viçosa, 2002. 235p.

VAZ, F.N.; RESTLE, J.; PEROTTONI, J. et al. Aspectos qualitativos da carcaça e da carne de machos Hereford inteiros ou castrados, abatidos aos quatorze meses. In: REUNIÃO ANUAL DA SOCIEDADE BRASILEIRA DE ZOOTECNIA, 36., Porto Alegre, 1999. Anais... Porto Alegre: Sociedade Brasileira de Zootecnia, 1999. p.335.

VAZ, F.N.; RESTLE, J. Aspectos qualitativos da carcaça e da carne de machos Hereford, inteiros ou castrados, abatidos aos quatorze meses. Revista Brasileira de Zootecnia, v.29, n.6, p.1894-1901, 2000.

VAZ, F.N.; RESTLE, J.; FEIJÓ, G.L.D. et al. Qualidade e composição química da carne de bovinos de corte inteiros ou castrados de diferentes grupos genéticos Charolês x Nelore. Revista Brasileira de Zootecnia, v.30, n.2, p.518-525, 2001.

WOOD, J.D. Consequences for meat quality of reducing carcass fatness. In: WOOD, J.D.; FISHER, A.V. (Eds.) Reducing fat in meat animals. London: Elsevier, 1990. p.344-397.

Recebido em: 22/04/03 Aceito em: 02/04/04 